\title{
Papers
}

\section{Evaluation of implementation and effect of primary school based intervention to reduce risk factors for obesity}

\author{
Pinki Sahota, Mary C J Rudolf, Rachael Dixey, Andrew J Hill, Julian H Barth, Janet Cade
}

\begin{abstract}
Objectives To implement a school based health promotion programme aimed at reducing risk factors for obesity and to evaluate the implementation process and its effect on the school.

Design Data from 10 schools participating in a group randomised controlled crossover trial were pooled and analysed.

Setting 10 primary schools in Leeds. Participants 634 children (350 boys and 284 girls) aged 7-11 years.

Main outcome measures Response rates to questionnaires, teachers' evaluation of training and input, success of school action plans, content of school meals, and children's knowledge of healthy living and self reported behaviour.

Results All 10 schools participated throughout the study. $76(89 \%)$ of the action points determined by schools in their school action plans were achieved, along with positive changes in school meals. A high level of support for nutrition education and promotion of physical activity was expressed by both teachers and parents. 410 (64\%) parents responded to the questionnaire concerning changes they would like to see implemented in school. 19 out of 20 teachers attended the training, and all reported satisfaction with the training, resources, and support. Intervention children showed a higher score for knowledge, attitudes, and self reported behaviour for healthy eating and physical activity.

Conclusion This programme was successfully implemented and produced changes at school level that tackled risk factors for obesity.
\end{abstract}

\section{Introduction}

The prevalence of childhood obesity is increasing throughout the world. ${ }^{1}$ Within the United Kingdom, estimates of obesity range from $6 \%$ in preschool children $^{2}$ to $17 \%$ by age $15 .^{3}{ }^{4}$ Because obesity may track into adulthood ${ }^{5}$ and adult obesity is difficult to treat, prevention strategies are best targeted at children. $^{4} 67$

Most obesity interventions have taken place in clinical settings. However, schools also provide an opportunity for preventing and treating obesity. ${ }^{49}$ Most school based approaches have targeted obese children, with most success in primary school aged children. ${ }^{10}$ An alternative strategy is to implement a primary intervention health promotion programme aimed at all pupils. Again, these initiatives have had some success in the United States, ${ }^{8}$ although more specific interventions targeted at the different factors influencing children's eating and physical activity behaviours (classroom education, food service, parents) may be needed. ${ }^{9}$

Despite major resources being deployed towards encouraging health promotion in schools in the United Kingdom, no rigorously designed intervention studies of programmes targeting obesity have taken place. ${ }^{11}$ Health promotion programmes are unlikely to be successful if the programme is of poor quality or has not been efficiently implemented. ${ }^{12}$ This paper describes and evaluates the implementation of a health promotion programme in primary schools to prevent risk factors for obesity. The outcome measures relating to weight, diet, and activity, which we evaluated by a randomised controlled trial, are reported separately. ${ }^{13}$

\section{Participants and methods}

Intervention programme

The active programme promoting lifestyle education in school (APPLES) was designed as a multidisciplinary, multiagency programme using a population approach that was underpinned by the Health Promoting Schools philosophy. ${ }^{14}$ This philosophy aims to link the school with family and community and focuses on the whole school ethos, including its policies, management style, and attitudes of staff, so that consistent health messages are given and received.

The programme's team included a dietitian (project manager), a community paediatrician, a health promotion specialist, a psychologist, an obesity physician, and a nutritional epidemiologist. The programme targeted the whole school community including parents, teachers, catering staff, and the school environment. It was designed to take place over one academic year and was based on the concept of school action plans, which were to be developed by the individual schools on the basis of their perceived needs. The programme was intended to influence dietary and physical activity behaviour and not simply knowledge in the school children.

The team provided training for teachers and some resources, and the project manager also provided input and contacted the schools regularly throughout
Editorial

by Atkinson

School of Health

Sciences, Leeds

Metropolitan

University, Leeds

LS1 3HE

Pinki Sahota

senior lecturer in

nutrition and dietetics

Rachael Dixey

principal lecturer in

health promotion

Leeds Community

and Mental Health

Trust, Belmont

House, Leeds

LS2 9DE

Mary C J Rudolf

consultant community

paediatrician

School of Medicine,

Leeds University,

Leeds LS2 9LT

Andrew J Hill

senior lecturer in

behavioural sciences

Leeds General

Infirmary, Leeds

LS1 3EX

Julian H Barth

consultant in chemical

pathology and

metabolic medicine

Nuffield Institute of

Health, Leeds

LS2 9PL

Janet Cade

senior lecturer in

nutritional

epidemiology

Correspondence to:

M C J Rudolf

Mary.Rudolf@

leedsth.nhs.uk

BMJ 2001;323:1-4 
the year to give support. The underlying approach was to be non-prescriptive and to ensure ownership of the programme by the schools.

\section{Participants}

Ten state primary schools in Leeds were enrolled into the project as described in the accompanying article. ${ }^{13}$ Sociodemographic measures suggested that they were somewhat advantaged schools, with 1-42\% of children from ethnic minorities and $7-29 \%$ entitled to free school meals (compared with $11 \%$ and $25 \%$ for Leeds children as a whole).

Children in years 4 and 5 (8-10 year olds) received the programme. This age group was chosen because the prevalence of overweight increases at around this age, the children were able to cooperate with questionnaires, and collection of data could be completed before they left primary school.

In 1996, the schools were randomised to receive the programme or serve as controls for that year. The five control schools received the intervention the following year. To evaluate the implementation and effect of the programme, we pooled data from the 10 schools.

\section{Design and development of intervention}

To inform the design and development of the intervention, questionnaires were administered to all school staff, including secretarial and catering staff, and parents of year 4 and 5 pupils. The questionnaire asked for views about the importance of education on nutrition and physical activity and whose responsibility that should be. In addition, parents were asked about changes they would like to see in school and information they would like to receive. The responses

Table 1 Numbers (percentages) of school staff and parents who agreed with statements regarding educating children about healthy lifestyle

\begin{tabular}{|c|c|c|}
\hline & $\begin{array}{l}\text { School staff } \\
(n=124)\end{array}$ & $\begin{array}{l}\text { Parents } \\
(\mathrm{n}=410)\end{array}$ \\
\hline It is important for schools to take a major role in promoting the health of children & $109(88)$ & $377(92)$ \\
\hline $\begin{array}{l}\text { There should be an emphasis on teaching about balanced eating and physical } \\
\text { activity in school }\end{array}$ & 117 (94) & 385 (94) \\
\hline Schools should have a food policy & $83(67)$ & $287(70)$ \\
\hline $\begin{array}{l}\text { The family alone should not be responsible for their child's food habits and } \\
\text { physical activity }\end{array}$ & $120(97)$ & $328(80)$ \\
\hline Schools should be responsible for encouraging physical activity & $108(87)$ & $390(95)$ \\
\hline A child's diet affects its health & $113(91)$ & $373(91)$ \\
\hline A child's diet affects its health in adulthood & $109(88)$ & $349(85)$ \\
\hline
\end{tabular}

Table 2 Summary of changes and information requested by parents when surveyed about the sort of input they felt was required in school

\begin{tabular}{lr}
\hline Changes suggested & $\begin{array}{c}\text { No (\%) } \\
\text { of parents } \\
\text { (n=410) }\end{array}$ \\
\hline Promotion of healthier breaktime snacks with enforcement by school & $160(39)$ \\
\hline Playground activities: organised games and balls, hoops, and skipping ropes to be made available & $139(34)$ \\
\hline Healthier school meals (fewer chips and more fruit, vegetables, salads, pasta, jacket potatoes) & $135(33)$ \\
\hline More games and sports and wider variety for all age groups & $131(32)$ \\
\hline Ideas for healthier packed lunches & $66(16)$ \\
\hline Joining in games and activities and tasting sessions in school & $139(34)$ \\
\hline Parents offering skills (dance teachers, food tasting and cooking, sports coaching) & $25(6)$ \\
\hline Information requested & $160(39)$ \\
\hline Material on healthy eating for children & $148(36)$ \\
\hline Fun physical activity ideas & $115(28)$ \\
\hline Main meal ideas & $66(16)$ \\
\hline Breaktime snack ideas &
\end{tabular}

from these questionnaires were used by schools to develop the school action plans. The progress towards these targets was monitored by regular staff meetings and surveys of packed lunches, breaktime snacks, and playground activities

Response rates to these questionnaires were taken to reflect the support of parents and teachers for the programme. We also used the completion of diaries by children as a measure of commitment by children and parents, and data on growth and 24 hour recall of diet and activity questionnaires as a measure of commitment by the schools.

Changes regarding school meals were discussed with the local education authority catering organisation, which agreed that the team would work directly with the catering staff in schools. Meals were monitored by discussions with staff, collection of monthly menus, and observation of lunches on offer. We assessed whether quality had improved over the year.

An anonymous questionnaire was administered to teachers at the end of the intervention to evaluate the quality of the teachers' training, the usefulness and appropriateness of the resources, and the adequacy of support offered and to ascertain whether the programme had had an effect in the schools. We also collected information on support taken up by the schools over the year.

\section{Focus groups}

To determine the effect on children's levels of knowledge and attitudes towards healthy living, we held focus groups in schools at the end of the first year. Details are available in the accompanying paper. ${ }^{14}$

\section{Results}

We received questionnaires from 124 school staff before the intervention (62 teachers, 13 non-teaching assistants, 23 special needs assistants, 17 catering staff, and 9 administrative staff). The questionnaire administered by pupil post was completed by $410(64 \%)$ of parents; response rates ranged from 39\% to $85 \%$ between schools. Table 1 shows the responses of parents and staff to questions relating to the importance and relative responsibility of home and school in engendering a healthy lifestyle in children. Table 2 shows the changes in the school environment that parents hoped to see and the information they felt would be useful. Feedback to the questionnaire and changes within the school were circulated to parents during the year.

\section{Response rates}

Table 3 shows that data were available for over $90 \%$ of pupils for most measures, indicating excellent participation in the programme by schools and staff. Response rates for the three day diet and activity diaries were satisfactory and indicated a good level of commitment by both children and parents.

\section{Support and training}

Nineteen out of 20 teachers attended the training sessions. In anonymous questionnaires at the end of the intervention, all reported that they found the training useful, that the resources were useful and they would continue to use them, that support during the project 
Table 3 Number (percentage) of responses for data collected

\begin{tabular}{llc} 
& $\begin{array}{c}\text { Baseline } \\
(\mathbf{n}=\mathbf{6 3 6})\end{array}$ & $\begin{array}{c}\text { At } \mathbf{1 2} \text { months } \\
\mathbf{( n = 6 3 2 )}\end{array}$ \\
\hline Anthropometric data & $613(96)$ & $596(94)$ \\
\hline Diet and physical activity (24 h recall) & $583(92)$ & $594(94)$ \\
\hline 3 day diet and physical activity & $403(63)$ & $407(64)$ \\
\hline Psychological data & $593(93)$ & $591(94)$ \\
\hline Parents' questionnaire & $410(64)$ & \\
\hline
\end{tabular}

Table 4 Examples of support offered by project manager and uptake by schools

\begin{tabular}{lc} 
Type of activity & No of schools \\
\hline Class sessions on healthy eating & 10 \\
\hline Competitions & 10 \\
\hline Involvement in food awareness week & 10 \\
\hline Attendance at parents' evenings or open days & 4 \\
\hline Health weeks & 4
\end{tabular}

was good, and that they had an increased awareness of healthy eating and physical activity among pupils.

The project manager offered a variety of ways that she could support the schools in implementing their action plans. Table 4 shows the types of activity offered and the uptake by the schools. All opted for direct input in the classroom, competitions, and involvement in a food awareness week.

\section{School action plans}

All schools elected to incorporate nutrition education into the curriculum, with additional sessions supplied by the project manager (table 5). They also included a "fit is fun" programme in physical education lessons and undertook to improve their health resources. In total, there were 85 action points with six to 14 points per school plan; $76(89 \%)$ of these points were successfully achieved. Reasons for not achieving action points included shortage of time, staff sickness, and impending inspection by government teaching standards officers.

\section{School meals}

Given the emphasis on healthy eating, school meals were an important aspect of the assessment. Positive changes were seen in all schools (table 6).

\section{Focus groups}

Compared with other children, children who had received the intervention showed greater understanding of the health benefits of diet and physical activity; sophistication of ideas and vocabulary expressed; willingness and confidence to share their ideas as well as basic knowledge. They also reported behaviour changes and were more able to recollect topics learnt and activities in school linked to diet and physical activity.

\section{Discussion}

The evaluation of the implementation of this programme to reduce risk factors for obesity in children shows that the project was successful. Parents and school staff clearly felt that school was an important site for influencing children in their lifestyle and were supportive. The response rates for questionnaires were high, reflecting the children's and staff's eagerness to participate and commitment to the project. The schools were ready to accept support and input at both the school and classroom level.

The results also show that the programme had a noticeable effect in the schools. Eighty nine per cent of the action points in the school action plans were implemented, and there were positive changes in classroom health education, the physical education programme, and the school food service. ${ }^{9}$ School meals were also improved.

The focus groups supported the sense that the programme had had an effect at school. The children who had participated in the project readily and enthusiastically recalled the activities in which they had been involved. These children also scored higher than did children who had not yet received the programme in terms of knowledge of healthy eating, physical activity, and links between diet and health including obesity. They also attained higher scores for self reported behaviour change.

\section{Ways to tackle obesity}

Schools provide an excellent opportunity for preventing and treating obesity. ${ }^{7-9}$ They offer continual regular contact with children and opportunities for nutrition education and promotion of physical activity both within the formal curriculum and informally through a supportive environment such as healthy school meals and breaktime snacks.

To date, information on effective programmes for prevention of obesity as well as results are largely missing. ${ }^{11}$ Although a healthy diet and exercise are probably unique components for such preventive programmes, currently there is no knowledge on how they should best be implemented.

Our programme used a population based approach underpinned by the Health Promoting Schools philosophy. ${ }^{14}$ The population approach ensured that all children including those at risk of developing obesity were included. As the prediction for

Table 5 Number of schools that included health promotion activities in action plan

\begin{tabular}{|c|c|}
\hline Activity & No of schools \\
\hline Nutrition education incorporated into curriculum & 10 \\
\hline Healthy eating class sessions delivered by dietitian & 10 \\
\hline $\begin{array}{l}\text { Fit is fun programme incorporated into physical education } \\
\text { lessons }\end{array}$ & 10 \\
\hline Improved or updated health resources & 10 \\
\hline Improved playground facilities & 7 \\
\hline Policy changes regarding breaktime snacks & 6 \\
\hline Healthy packed lunches & 6 \\
\hline Displays or competitions & 5 \\
\hline Invitation to outside agencies & 5 \\
\hline Healthy tuckshops & 4 \\
\hline Development of after school activities & 3 \\
\hline Healthy assemblies & 3 \\
\hline Other & 7 \\
\hline
\end{tabular}

Table 6 Food offered by schools at lunch time

No of schools

\begin{tabular}{lcc}
\cline { 2 - 3 } & Before intervention & After intervention \\
\hline Jacket potatoes & 1 & 10 \\
\hline Mashed potatoes & 4 & 6 \\
\hline Fresh fruit-daily & 8 & 10 \\
\hline Salad vegetables-daily & 4 & 7 \\
\hline Vegetarian options & Poor & Good variety
\end{tabular}




\section{What is already known on this topic}

Prevention of obesity is an increasingly important aspect of health promotion

Few trials have investigated school based primary prevention programmes directed at obesity

\section{What this study adds}

The programme was successful in producing school level changes to tackle risk factors for obesity

High levels of participation indicated support from schools, staff, parents, and pupils

Positive changes were seen in school meals, tuck shops, and playground activities

adult obesity from childhood measures is poor, ${ }^{5}$ a population approach should have more effect at the public health level than targeting children who are already obese. Furthermore, behavioural and environmental conditions that contribute to the development and maintenance of obesity might be modified.

The Health Promoting Schools philosophy ${ }^{14}$ is an approach that teachers can relate to, and which respects the professionalism and contribution of school staff while also viewing the child as part of a wider community. It extended beyond the classroom and ensured participation by schools, teachers, parents, caterers, and pupils in the development of the programme. This helped to ensure ownership and successful implementation.

This systematic evaluation has shown that risk factors for obesity can be successfully targeted in primary schools and that change can be achieved in the school environment and in children's knowledge base with relatively few additional resources. Given the positive effects achieved in all 10 schools, we believe the programme could be successful in other primary schools.
We thank the staff, pupils, and parents of Brodetsky, Cookridge, Fir Tree, Horsforth St Mary's, Moortown, Morley The Newlands, Pudsey Lowtown, Shadwell, Springbank, and Whartons Otley primary schools for their participation, enthusiasm, and support. We also thank Nazia Chaudary and Julia Bartrop for conducting the focus groups and Gail Cook for helping with the evaluation of school meals.

Contributors: PS was the project manager and provided the main input into guiding and supporting the schools through the intervention. She collected and analysed the raw data, coordinated the programme, and drafted the article. MCJR was the principal investigator and coordinated the research team. She supervised the analysis and interpretation of the data and wrote the article jointly with PS. She will act as guarantor for the paper. RD provided the health promoting philosophy and guided the approach taken in designing the APPLES programme. She and $\mathrm{AJH}, \mathrm{JHB}$, and JC provided support in conducting the research and contributed intellectual input into the ideas behind and final format of the paper.

Funding: Northern and Yorkshire Region Research and Development Unit funded the research.

Competing interests: None declared.

1 World Health Organization. Preventing and managing the global epidemic. Geneva: WHO, 1997.

2 Reilly JJ, Dorosty AR, Emmett PM. Prevalence of overweight and obesity in British children: cohort study. BMJ 1999;319:1039.

3 Rudolf MCJ, Sahota P, Barth JH, Walker J. Increasing prevalence of obesity in primary school children: cohort study. BMJ 2001;322:1094-5.

4 Fruhbeck G. Childhood obesity: time for action, not complacency $B M J$ 2000;320:328-9.

5 Power C, Lake JL, Cole TJ. Measurement and longterm risks of child and adolescent fatness. Int J Obes Metab Dis 1997;21:507-26.

6 Dietz WH. Childhood obesity. In: Bjorntorp P, Brodoff BN, eds. Obesity. Philadelphia: Lipincott, 1992:606-9.

7 Garrow JS. Importance of obesity. BMJ 1991;303:704-6.

8 Reniscow K. School-based obesity prevention. Ann N Y Acad Sci 1993;699:154-6.

9 Story M. School-based approaches for preventing and treating obesity. Int J Obes 1999;23(suppl 2):S43-51.

10 Parcel GS, Simons-Morton BG, O'Hara NM, Baranowski T. School-based programmes to prevent or reduce obesity. In: Krasnegor NA, ed. Childhood obesity: a biobehavioral perspective. Caldwell, NJ: Telford, 1988:143-7.

11 NHS Centre for Reviews and Dissemination. The prevention and treatment of obesity. Effective Health Care Bull 1997;3 (No 2).

12 Tones K. The health promoting school: some reflections on evaluation. Health Educ Res 1996;11(4):i-viii.

13 Sahota P, Rudolf MCJ, Dixey R, Hill AJ, Barth JH, Cade J. Randomised controlled trial of primary school based intervention to reduce risk factors for obesity. BMJ 2001;323:1029-32.

14 Young I, Williams T, eds. The healthy school. Edinburgh: Scottish Health Education Group, World Health Organization, 1989.

(Accepted 12 July 2001) 